\title{
Watching, Attending, Sense-making: Spectatorship in Immersive Theatres
}

DOI 10.1515/jcde-2016-0004

Abstract: This article addresses the aesthetic, corporeal and intellectual dimensions of spectatorship in immersive theatre. Immersive work engages audiences at an experiential level and within environments that prompt multisensory engagement and explorative forms of audience participation. Immersive theatre makers, such as De La Guarda, dreamthinkspeak and Punchdrunk, have been making internationally recognised work throughout the 21st century. While audience interaction and participation has attracted a great deal of scholarly attention over the past few years, the significance of watching in immersive theatre remains elusive and merits further consideration. Drawing on Immersive Theatres (Machon, 2013) and referencing a full range of practice that is exemplary, this article describes and defines 'immersive theatres' in broad terms. Using Punchdrunk's The Drowned Man (2013) as illustration, it considers the types of experience to be had and the qualities of watching that result in such events. In turn it addresses the type of 'sense' individuals can make when they are spectators to their own interactions, attendant to their actions and reactions.

Keywords: embodied spectatorship, immersive, interaction, Punchdrunk, (syn)aesthetics, The Drowned Man

\section{Introduction: Looking in, Looking out, Looking}

\section{on...}

Artists who harness more than our eyes and ears encourage us to wake up, to be alert to the world around us, and to interact actively with the objects and creatures around us. It is an invitation to live, to feel, and to be part of a larger community. (Di Benedetto 134)

I'm in the dressing room. Alone. Shadows. The pungent aroma of greasepaint with powdery overtones of musk and tulle hangs around me and I briefly catch myself looking back at myself in the illuminated mirror, a grainy-ghostly silhouette reflected in the glass. My hands hover over

*Corresponding author: Josephine Machon, E-Mail: j.machon@mdx.ac.uk 


\begin{abstract}
the table, purposefully pick up a scarlet lipstick that lies amongst the detritus of cheap glamour. I absorb the flimsy solidness of the metal-case, the scent of it. I put it down and pick up the postcard that lies next to it. As I do so I feel the presence of another, of others, entering the space. In the same moment I look up to see a scarlet-lipped woman silently-sinuously choreographing herself into the room. She's followed by masked observers, clumsy in contrast in their eagerness to keep up with her while remaining in her wake. I turn to watch her. She continues towards me and I feel her undulating movement through my gaze, my arms, my legs, my torso; a perceptual mirroring of her motion. I shift aside as she heads to the dressing table. She doesn't register me and nor do the crowd that follow her. No need to. I'm that grainy ghostly reflection; a present-absence, absent-presence. So I gently move back into the gloom and watch her from over there.
\end{abstract}

This opening reflection on my reflection in the mirror of the dressing room within Punchdrunk's The Drowned Man (2013) is a way into my critical reflections on some of the aesthetic, corporeal and intellectual dimensions of spectatorship in immersive theatre. Central to this is a consideration of the nature of spectating itself in immersive practice, comprising a fusion of internal and external interactions. The heightened sensual perception involved impacts on the type of intellectual sense that can be made when we are spectators to our own experience - when we attend to our actions, reactions and interpretations.

\title{
Immersive Theatres
}

The term 'immersive' is currently used widely to define a style of performance practice and applied to diverse events that seek to exploit all that is experiential in performance. From the outset, I wish to emphasise that a lot of theatre is experiential and works on its audience in a visceral manner; immersive practice is just one strand of that. Indeed, qualities attributed to 'the immersive' have described interdisciplinary, sensory and participatory performance work occurring in places outside of traditional theatre venues for a good while. Accordingly, the term is now used freely (sometimes excessively) to describe contemporary performance practice involving a visceral and participatory audience experience with an all-encompassing, sensual style of production aesthetic. That said, although heterogeneous in form, there are central features that go some way to identifying how far an event is immersive. In brief, the event should always establish an 'in-its-own-world'-ness where space, scenography, sound and duration are palpable forces that comprise this world. To allow full immersion in these worlds, some kind of 'contract for participation' is shared early on between the spectator and the artist, inviting and enabling varying modes of agency and 
participation. ${ }^{1}$ These contracts may be explicit in written or spoken guidelines shared prior to entering the space, or implicit within the structures of the world that become clear in a tacit fashion as an individual journeys through the event or a combination of the two. On entering these immersive domains, spectators are submerged in a medium that is different to the 'known' environment and can become deeply involved in the activity within that medium, all their senses engaged and manipulated. Bodies are prioritised in these worlds, possibly performing and always perceiving bodies - the latter belonging to spectators, whose direct insertion in and interaction with the world shapes and transforms potential outcomes of the event.

This live, immediate interaction, the spectator's physical body responding within an imaginative environment, is a pivotal element and thus a defining feature of immersive theatre. It is in this way that the role of the spectator shifts from the usual requirements of an attendee at a theatre performance. The presence and participation of the audience member within the work ensures she or he inhabits the immersive world created. This creative agency, involving processual interaction through the event, shapes the unique journey for each participating individual. ${ }^{2}$ Their decision-making processes result in a variety of interpretations and outcomes during and following the event, which underlines the uniqueness of each experience for every individual. This radical repositioning of the performance / spectator relationship destroys the binaries of auditorium / stage and spectator / performance, relocating the relationship conceptually, spatially and physically. The audience is fundamentally complicit within the form and content,

1 These contracts are to enable active, physical participation and are thus different to the 'accepted' or 'usual' set of rules and conventions of 'traditional' theatrical performances. 'Traditional' or 'conventional' in this particular context (and accepting that these are contestable terms themselves) suggests a theatre experience, often associated with a proscenium arch, where audiences enter an auditorium, sit in their assigned seat in a given row, obediently hush as soon as the house-lights dim and stage lights come up and, perhaps, a red, velvet curtain is raised. Audience members applaud at the end of each act, take a drink in an interval after which they return to their seats and as the performance ends, there is final applause for the 'curtain call' and they leave. These rules and conventions are in place in any 'spectatorial' theatre production where the audience / actor (us / them) relationship is defined by the delineation of space (auditorium / stage) and role (static-passive observer / active-moving performer), and the audience is viewing the action ahead of them.

2 'Processual' here is adopted from gaming terminology and highlights the variation in each individual spectator's experience due to 'player' / spectator decision-making processes. As Gordon Calleja clarifies, digital games are "processes that create carefully designed, unpredictable interpretations" where "both the game practice and the meaning it generates are subject to change" (10-11). 
a living part of the aesthetic and a crucial element of any structural, narrative or thematic composition. ${ }^{3}$

\section{Involving / Evolving the Spectator}

Susan Bennett's singular study considering the cultural phenomenon of the theatre audience recognised that "the involvement of the audience in the theatrical event is undoubtedly complex" (204). In light of this, spectating is now widely understood to be a multilayered activity in much contemporary performance. Furthermore, the purposeful manipulation of the senses in certain works, which shifts both the notion and experience of spectatorship, has been the forefront of theatre and performance analysis in recent years. ${ }^{4}$ Immersive events in particular have seen to an evolvement through involvement of a particular kind of audience. Beyond theatregoers who are keen to engage with experimental work, immersive performance is attractive to an alternative audience from underground scenes, cabaret circuits and festivals. It caters for an audience that enjoys opportunities for community and conviviality where verbal and physical interaction is actively encouraged; an audience that is hungry for emotional and physical human connection. In a desire to develop new ways of enticing such an audience, immersive practitioners continue to construct new forms of engagement, which, in turn, evolves the form and functions of immersive practice.

Full immersion always involves degrees of interactivity and improvisation on the part of spectator as much as artist, which must be shaped expertly by the practitioner. An audience member may find herself taken into a bizarre world via video goggles and headphones, where she responds in the moment to audio instruction and physical manipulation as its sights, scents, sounds and spatial effects become palpably present, created by unseen performers, as in Il Pixel Rosso's work. In Kate Bond and Morgan Lloyd's You Me Bum Bum Train (2010), her improvisation may entail influencing live performers' actions as she takes on

3 See Machon's Immersive Theatres (70-102) for a more detailed overview which addresses the quintessential features of immersive theatre and considers what it is in relation to form, aesthetic and experience that defines this performance practice and sets it apart from the conventions of traditional, 'spectatorial' theatre or other forms of affective performance.

4 For example, Sally Banes and André Lepeckis’s The Senses in Performance (2007), Erin Hurley’s Theatre \& Feeling (2010), Martin Welton's Feeling Theatre (2011), Josephine Machon's (Syn) aesthetics: Redefining Visceral Performance (2011), or Nicola Shaughnessy's Affective Performance and Cognitive Science (2013) all explicitly address this area. 
multiple roles - a supply teacher to a class of rowdy teenagers, a coach, geeing up a soccer team, the ringleader of a bank heist. A spectator's role may be provided online in advance of her arrival at the venue, to be developed by her actions and reactions as the piece progresses, deciding the fate of her community, as with Coney's A Small Town Anywhere (2009) or, more recently, the fate of the country in Early Days (of a better nation) (2014). Alternatively, the audience's quick-wittedness as part-authors, part-gamers, will be tested when it constructs the theme, narrative and imagined space of the event with the artist, as in Seth Kreibel's The Unbuilt Room (2013) - snap decision-making is required on each audience member's part, acutely aware that the 15 minutes granted to the group are ticking by on the stopwatch under Kreibel's chair. In Punchdrunk productions one can involve oneself deeply simply by interacting as one chooses with the scenographic detail of the space - to pull open drawers and rootle around for clues to the story, to sniff the faded scent in perfume bottles and get under the skin of its owner. Such improvisations for many are a liberating and pleasurable play in the performing moment. For others, the invitation to interact and choreograph their way through the performance is more dangerous, disturbing or simply irksome, in the onus it places on them to take care, or perhaps take charge, of their part in the work.

What becomes clear through these examples is that the terms 'spectator' and 'audience' are inadequate in defining the specific activity of those receiving the work. Alternative names have arisen amongst immersive practitioners, such as the late Adrian Howells's 'audience-participants', Coney's 'playing-audience', Lundahl \& Seitl's 'visitors' and Rotozaza's 'guest performers'. These labels indicate a rejection of any traditional spectatorial set-up and the hierarchical attitude it invites which, at worst, encourages a relationship of "judgement", as Howells suggests, as opposed to one of connection through shared responsibility (see Machon, Immersive Theatres 261).

Alison Oddey and Christine White provide a useful overview of the complexities inherent to 21st-century 'modes of spectating'. Spectatorship today means more than "merely looking" and is reconsidered and defined by "interactivity" in manifold ways (12-13):

Audience - is a group of people who have come to watch, but more importantly to hear in a space that equates to an auditorium. Hearing related not necessarily to seeing, as the Elizabethans described going to hear a play. Spectator - is an onlooker, wholly related to viewing and observation. However, the definitions of both these activities in the twenty-first century collide. They not only require listening, but both looking and observation, action and integration, and interactivity. (Oddey and White 12-13, emphasis original) 
'Inter' here is "in the sense of between and among and belonging in common to" - all terms which "relate to spectating activities" (Oddey and White 13). 'Inter' is also, for Oddey and White, "a prefix to the senses, as is all twenty-first century spectatorship" (13). Significantly, the action of watching involves "being on the alert and keeping in view" (Oddey and White 13). Watching, then, is understood as an active state, not a passive looking on without necessarily noticing.

In live, immersive events the 'inter' is emphasised and the skills that are attributed to audience, spectator, observer and watcher are combined and evolved within the role of 'immersive interactor', a decision-making participant in the process. The interactor becomes watcher-observer-improviser-adventurer-collaborator. The name plays on the notion of spectator as role-taker in a performance event, while emphasising the possibilities for the spectator to act in close relation to performers, object and space, embracing the reciprocal action and influence that can exist as a consequence of the multiway transfer of information and activity within immersive work. My use of this term also borrows from physics in regard to the potential transfer of energy between the interactor, the space and the performers that is peculiar to many immersive events. By employing 'interactor', my aim is to accentuate the affective nature of such experiences.

\section{Watching, Attendance and Praesence}

A vital component of immersive theatre, then, is the fact that it revels in an energised liveness and the consequent live $(d)$ ness of the performance moment. To clarify, whatever forms the imaginative journey through the event takes, the sensual worlds created for and through immersive practice exploit the unique power and theatricality of live performance as an artistic medium. A very real exchange of energy between humans exists within the immediacy of the live and ongoing present of performance. A sense of being alive - more significantly, an awareness of the lived moment - is keenly felt. This connects with Gilles Deleuze's theories of "immanence" as "pure presence" (Deleuze, Francis Bacon 52) brought about by visceral artworks where the sensation of being "in the moment" generated by the work itself activates "an absolute immediate consciousness" (Deleuze, Pure Immanence 27). With immersive work, the sense of "between-times, betweenmoments" (Deleuze, Pure Immanence 29) comes about due to the felt, live(d) quality of every second of the duration of the piece. Artworks that harness this live(d)ness can actuate a lasting ephemerality - the paradoxical experience, particularly attributable to immersive practice, where the live performance of the work is fleeting and only of the moment, yet it also lasts in the interactor's embodied memory of the event as a pleasurable and / or disquieting impression that remains. 
The intersensual activity of the interactor in immersive practice includes acts of observation that trigger embodied watching. This is a noticing of internal feelings (both emotional and sensational) as much as external occurrences - a giving attention, moment by moment. In such instances, even when shifting back to look on, the watcher remains active, attending to the moment, to what it looks like but, more significantly, what it feels like, both internally and externally. By doing this, the interactor becomes, to use Stephen Di Benedetto's term, "attendant", "implying presence and participation" (126), as in attending to an action or experience. Giving meaningful embodied attention to presence and participation involves a significant shift from the usual spectatorial role of being in attendance' as in 'in servitude' to a production. ${ }^{5}$

Here 'presence' directly correlates to its etymological roots, from praesens, 'to be before the senses' (prae, 'before'; sensus, 'feeling, sense'). In immersive theatre, this attention to the senses is acutely and haptically perceived rather than a dormant feature of spectatorial engagement. ${ }^{6}$ The spectator is aware of the involvement of the senses and this heightened awareness is often central to the immediate experience and any subsequent analytical interpretations. Many immersive practitioners activate praesence by using preparation techniques to gently immerse participants in the world - pre-performance rituals and framings to acclimatise the interactor within the work; antechambers where one is masked, introduced to characters or guides who initiate interactors into the world, as with Punchdrunk's signature events; waiting rooms which gently steep participants in the outlandish environment, as with the work of dreamthinkspeak or Il Pixel Rosso; or clever soundscapes through the intimacy of headphones that take one into the world of the event, having imperceptibly merged with the ambient sounds of the world one is leaving behind, as with Lundahl \& Seitl's work. Activating the imagination and proprioceptive senses in such ways enables interactors to intuit their way through the event.

The mask in Punchdrunk's work is an interesting mechanism that enables affective involvement. It is a requirement that the audience in large-scale produc-

5 'Meaningful' as opposed to an inadvertent awareness of the immediate environment and its physical repercussions - one's discomfort in a seat or the snores of a co-spectator which distract from the performance in progress. Such embodied attention is not invited by the practitioner and is certainly not intended to add to the interpretation of the work.

6 I use 'haptic' and 'haptically' (from the Greek, haptikos and haptesthai, 'to grasp', 'sense', 'perceive', 'lay hold of'), alongside 'tactile'. Where 'tactile' and 'tactual' connote the surface quality of touch, 'haptic' emphasises the tactile perceptual experience of the body as a whole (rather than merely the fingers) and also highlights the perceptual faculty of bodily kineasthetics (the body's locomotion in space), which incorporates proprioception (stimulation produced and perceived within the body relating to position and movement of the body). 
tions wear white, skeletal, beaked visors reminiscent of those worn at Venetian masquerades, which may only be removed in the liminal space of the bar or by a performer, should the interactor be chosen for an elusive one-on-one. The mask is a critical device in audience involvement, shifting status and encouraging interaction. The impact of the mask differs for each individual. Although some find the wearing of masks restrictive or feel foolish, for others it can liberate. The masks can invite playfulness, suggest role-play, grant permission to be curious, to become part of the otherworldliness or simply sit back and be. The effect is that audience merges with mise-en-scène - eerily present witnesses, no longer spectators but spectres in the shadows.

\section{'Being at Hand': Haptic Attention and the Importance of Touch}

Embodied attention through sensual interaction may be elucidated further when considering the Latin root of 'present'. This accounts for a state of being or feeling via tactile proof where praesent is understood as 'being at hand', 'being before' (from praeesse; prae, 'before' and esse, 'be'). 'Being at hand' is highly relevant to immersive practice, as the form encourages the spectator to touch and be touched by the event. As Rosalyn Driscoll, sculptor and sensory artist, asserts: "Touching grounds the aesthetic experienced in the body - in muscle and bone, gut and heart. Touching is the body asking questions and finding answers [...], not a bloodless, intellectual exercise but a somatic, sensory knowing by the body-mind [...]. The participation of the body in exploring art expands the possible sources of meaning” (111). Juhani Pallasmaa, a Finnish architectural philosopher, suggests that "the creative state is a condition of haptic immersion where the hand explores, searches and touches independently" (Thinking Hand 72; emphasis added). In this respect, the creative state in immersive practice is literally placed in the hands of the interactor. As Felix Barrett, Artistic Director of Punchdrunk, puts it, "[t]ouch is arguably the most pure and potent sense in these worlds” (qtd. in Machon, Immersive Theatres 162). Punchdrunk's work ensures that sight becomes tactile through encouraging interactors to look and look again at its sensual aesthetic, which results in a tangible connection with the world, accentuated by opportunities to touch and interact physically with space, objects and performers.

Laura Marks, film theorist and advocate for the haptic nature of watching, argues for critical approaches to appreciation that embrace "haptic visuality and haptic criticism", restoring "a flow between the haptic and the optical that our 
culture is currently lacking" (Touch xiii). ${ }^{7}$ For her, eyes can "function like organs of touch" (Skin of the Film 162). Similarly, performance theorist Gianna Bouchard asserts, "touch is an integral part of the dynamics of corporeal intervention" and artistic representations and methods that approximate the sensation of haptic vision allow "a slide to occur between vision and touch" (165). Where the sensuality of performing bodies and designed space is emphasised, Rebecca Schneider's arguments for "sensate involvement" enhanced by "eyes which touch" come to the forefront (32). In the heightened moment of an immersive experience, watching becomes tactile - it encourages "embodied vision", a haptic perception that is able to see 'beyond the visible' (Schneider 22-36).

It is often the case in immersive work that sight is manipulated in order to activate haptic involvement. Vision may be controlled by devices such as Oculus Rift or video goggles that create fantastical worlds literally in front of one's eyes, as with Il Pixel Rosso projects. ${ }^{8}$ Sight may be restricted or removed through shifts of shadow, blackout or blindfolding, as with the use of whiteout goggles or blackouts in Lundahl \& Seitl's work or the play with candlelight and shadow in Punchdrunk's realms. Practitioners may carefully direct the interactor's gaze to foreground the otherworldliness that exists within the everyday, as Berlin Nevada's Pinocchio (2007) illustrates. In this piece, performed for an audience of three for the duration of a short, bizarre car journey, the soundtrack and surreal performance within the enclosed world of the car make strange the window (windscreen) onto the outside world. This haptic manipulation of the watcher's gaze causes a heightened experience, which ensures everything that is perceived during the journey, including that 'outside world', becomes unusual, dreamlike. ${ }^{9}$

Pallasmaa's theories offer further insight here. He suggests that "[c]reative work calls for a double perspective: one needs to focus simultaneously on the world and on oneself, the external space and one's inner mental space. All artworks articulate the boundary between the self and the world, both in the experience of the artist and in that of the viewer/listener/occupant" (Thinking Hand 19-20). Removing sight in an immersive performance summons this double perspective by heightening those senses often deemed as secondary - smell, taste, touch, hapticity. In turn, touch and haptic perception enable the interactor

7 Marks argues that criticism that seeks to translate an artwork should echo its forms and ideas, meet it with sympathetic tones and textures - "haptic criticism is mimetic: it presses up to the object and takes its shape" (Touch xiii).

8 Oculus Rift is a trademarked virtual reality headset involving a 360-degree tracking system that enables a sensation of presence, currently used in gaming and virtual reality films (see https:// www.oculus.com/en-us/).

9 A short archive of Berlin Nevada's Pinocchio is available at <https://vimeo.com/29399171>. 
to be sentiently engaged with the world. At the points one is sighted, one is encouraged to look and look again, to look with the whole body and attend to the situations, narratives and ideas all around. The double perspective comprises a facilitated awareness that one is observing oneself from inside oneself, which correlates to the way in which one comprehends and interprets the piece - an activation of insight in all its variations.

\section{Watchful Inhabiting}

This blurring of external and internal space in immersive artworks - as composed by the artists and holistically comprehended by the interactors - inspires a sense of occupying the experience as much as the space. Punchdrunk in particular explore and exploit the narratives and sensual aspects of a space to these ends. Punchdrunk's practice combines Pallasmaa's theories of peripheral and focused vision within the sensual scenography of each production (see Pallasmaa, Eyes of the Skin 9-13). Peripheral vision accustomises an interactor to the "enveloping spatiality, interiority and hapticity" of a space which centres the inhabitant, and focuses embodied attention by returning her to a "preconscious perceptual realm [...] experienced outside the sphere of focused vision" (Pallasmaa, Eyes of the Skin 13). Punchdrunk's designers Livi Vaughan and Bea Minns, working closely with Barrett, allow the peripheral perception of the space (which embraces spatial and bodily experiences) to fuse with the sharp, focused vision of the detail in space. Intricate scenographic designs are a response to the peripheral ambience and implied stories of a site, while homing in on the dimensions and details of specific locations within it - the tones, textures and features that resonate with the themes and narratives of the work. For The Drowned Man, the company responded to the vast expanse of a disused postal sorting office in London, opposite the bustle of Paddington Station. Punchdrunk transformed the four levels of each floor into two mirrored worlds - Temple Studios, a darkly glamorous, early 1960s Hollywood studio populated by desperate actors, silent assistants, a dangerous diva and an unseen, omnipresent producer, Mr. Stanford; in stark contrast and lying back-to-back, a dusty, sweltering small-town on the outskirts of the Californian desert is home to the trailer-housed extras and studio wannabes. When on the inside, whole-body attention is drawn to the environment and the stories that it tells via a combination of localised scenographic detail and intimate choreography with the peripheral experience of light, sound, scent and far-off action.

It is when dwelling in these rooms, immersed in Punchdrunk's intricate worlds, that one becomes attuned to how different the act of spectating is in an end-on, three-act performance to these events. Entering a traditional theatre 
space makes us aware of the separateness of the world presented to us. Even when we might be placed in-the-round or in traverse, there is still a distancing that occurs as a consequence of the rules of engagement, the conventions by which we enter and inhabit that space and the visual / aural / technical formation of that space itself. The auditorium, the focus of the gaze, lighting configurations, exits and so on, all concede to "the dominance of the eye and then the ear, with a certain suppression of the other senses", pushing us into "detachment, isolation and exteriority" (Pallasmaa, Eyes of the Skin 19). The fourth wall of the proscenium arch and equivalent conventional theatre experiences frame the event to make it an "art of the eye" rather than facilitating a haptic sense of "human rootedness in the world" (Pallasmaa, Eyes of the Skin 19). ${ }^{10}$ Immersive work physically takes us into the world of the play, rather than inviting us to spectate and comprehend it from a distance in an auditorium. In most immersive practice, the space is integral to the experience. The audience is not separated from it but in it, of it. Interactors are surrounded by it, dwelling in it, travelling through it, which ensures some sense of 'rootedness' in the world of the event is actively felt. Attendance to the sensual exteriority of these worlds and the place that one takes within them can accentuate the individual interiority of the experience. This perceived fusion of external and internal sensation in the act of inhabiting underscores the double perspective of watching and witnessing within.

The Drowned Man expertly engaged this felt interplay of peripheral vision (requiring haptic, proprioceptive sentient powers) and sharply focused vision (bowing to the tactility of eyes and hands). These combined forms of perceptual apprehension encourage a rich, multilayered comprehension of the world and its inhabitants which, in turn, invites an equivalent response to themes and narratives that arise from the synthesis of its source texts, namely Georg Büchner's Woyzeck (1837/1879) and Nathanael West's The Day of the Locust (1939). The physical immersion in the world of the play allows for a unique appreciation of the work at hand - a deconstructive opening up of the multidimensional possibilities existing in each text. It enables the interactor to comprehend narrative and theme from the inside. Philosophical motifs and individual character psychologies are translated through sensual scenography, pervading sound and abstracted dance. This multiperspectival form grants visceral access to the literary and scholarly discourse of the source material. Ideas are felt, experiences are

10 Some performance events presented under traditional conditions can be open to sensual and experimental realisation due to the experiential qualities written into the text and production process, such as the work of Samuel Beckett, Caryl Churchill, Sarah Kane, debbie tucker green or myriad dance and physical ensemble productions - hence their affinity with immersive practice. I discuss such work at length in (Syn)aesthetics: Redefining Visceral Performance (2011). 
shared and understood in an embodied way. In The Drowned Man, it is possible to chart the narratives of William and Wendy, to follow one or other tragic plot (both, if you should choose to make repeat visits) by sticking with these characters as they play out their doomed parts. Equally, it is possible to lose them, lose oneself in the world, and lose sight of individual or wider stories that may exist. For those only seeking a straightforward path through a linear narrative, frustration, disappointment and dissatisfaction can be the result. Yet the wider themes and their implicit narratives are present and perceptible from the moment the mask is donned and the world is entered. The realisation that dreams can be lies; the terrible destruction that selfish desire and subsequent anger can wreak; the sense of individuals on the fringes, outcasts, powerless against looming, mass-mediatised worlds that are at odds with humanity, indifferent to human suffering - these are all made manifest through the multidimensional immersion in that world.

\section{Attending to Interpretation}

As these illustrations from Punchdrunk's The Drowned Man suggest, immersive work requires attention in immediate interpretation as much as it can inspire an unusual and lasting intellectual engagement. Sensory elision, especially between sight and touch, directly impacts on the nature of perception and the embodied memory that one has of the work in any subsequent processes of recall, including reimagining and analysing the work. My opening reflection indicated the importance of touch and haptic vision in Punchdrunk's work. Hands and eyes may lead perception, yet it is the correspondence between the whole human sensorium that is exercised in the experience of Punchdrunk's merging of scenographic design and performing / perceiving bodies. A (syn)aesthetic response is activated which shifts between realms - between the sensual and intellectual, between the literal and lateral - and relies on perception that comprehends the details of an event corporeally; its conceptual and thematic dimensions as much as its physical textures. ${ }^{11}$

Sensory involvement influences the tones and types of interpretation that are brought to bear. By activating imagination, instinct and intuition, immediate interpretation draws on an unusual feeling of 'knowing' where the fusion of

11 See Machon's (Syn)aesthetics: Redefining Visceral Performance (2011) for a detailed explication of (syn)aesthetics as an approach to appreciating and analysing experiential performance in general, and Machon's Immersive Theatres: Intimacy and Immediacy in Contemporary Performance (2013; 103-113, 142-145) for its application to immersive theatre in particular. 
cerebral and corporeal cognition makes sense / sense of the work, triggered by the process of becoming aware of this blending of the senses within interpretation. Here any interpretation, initially triggered by smell, taste or touch and apprehended by haptic vision, is affective and experiential; semantic sense (cerebral meaning-making) cannot be disassociated from somatic sense (embodied feeling and analysis). The interactor may literally feel the ideas and experiences of the performance holistically, in the moment. The effect of such a response can ensure that this individual holds onto the moment and remembers this feeling corporeally in any subsequent interpretation of the work - a unification of the 'felt' and the 'understood' that mobilises the body-brain intellect in regard to concept, themes and form.

The live(d), praesent experience - the interactor's physical body responding within an imaginative environment - is a pivotal element of an immersive experience and a defining feature of immersive theatre. The experiential nature of immersive practice prioritises the making-sense / sense-making processes of human perception and interpretation, where emotion and intuition hold their own weight in meaning-making. Spectating becomes a whole-body pursuit; sharply focused visual and tactile perception combined with the haptic, peripheral appreciation of the space activates whole-body attendance and invites a multilayered comprehension. Within immersive worlds, inhabitants become attuned to dwelling - dwelling in time, in a space, dwelling in their activity during the event and dwelling, attentively, in their own bodies.

Following these principles of (syn)aesthetic analysis, immersive theatres encourage the interactor to understand the work on an embodied level without necessarily being able to describe or explain this. This sensory intellect follows its own rules of logic that are both separate from and often intrinsic to cerebral intellect. It can affect an unsettling and / or exhilarating process of becoming aware of the fusion of senses within interpretation. The original, visceral experience remains affective in any subsequent recall within the embodied memory of the work. Individual imagination is key to this sensory intellect, guided by poetic (re)inventions of space, time and activity. Immersive theatres imaginatively combine a range of elements and techniques to heighten and defamiliarise everyday action, and thus establish worlds that hover in-between the felt sensation of the 'reality' and the 'unreality' of the experience. The praesent quality of comprehension in an immersive performance activates Deleuzean 'immanence' where the feeling of being in the moment as a constant praesence can engender an innervating feeling of being alive. Perhaps, then, immersive theatre has become popular because it celebrates this feeling of 'aliveness'.

Expertly executed immersive events are governed by artistic codes of practice that allow the experience to feel free and lead to differing modes of creative 
agency. They have seen to the birth of the interactor, a reciprocally active and influential improviser who transfers physical, emotional and intellectual energy within the immersive event and has opportunity to take part-ownership of the creative state. Consequently, immersive performance has evolved the idea and the practice of the spectator into an alert, watching, decision-making collaborator, an attendant-improviser who shapes form, influences function and transforms possible outcomes in the work, in the process sharing a responsibility and respect for the experience with the artist.

\section{Works Cited}

Banes, Sally and André Lepecki, eds. The Senses in Performance. London and New York: Routledge, 2007. Print.

Bennett, Susan. Theatre Audiences: A Theory of Production and Reception. 2nd ed. London and New York: Routledge, 2003. Print.

Bouchard, Gianna. "Haptic Visuality: The Dissective View in Performance”. Modes of Spectating. Eds. Alison Oddey and Christine White. Bristol and Chicago: Intellect, 2009. 161-76. Print.

Calleja, Gordon. In-Game: From Immersion to Incorporation. London and Cambridge: MIT P, 2011. Print.

Deleuze, Gilles. Pure Immanence: Essays on A Life. Trans. Anne Boyman. New York: Zone Books, 2001. Print.

Deleuze, Gilles. Francis Bacon: The Logic of Sensation. Trans. Daniel W. Smith. London and New York: Continuum, 2004. Print.

Di Benedetto, Stephen. “Guiding Somatic Responses within Performative Structures: Contemporary Live Art and Sensorial Perception". The Senses in Performance. Eds. Sally Banes and André Lepecki. London and New York: Routledge, 2007. 124-34. Print.

Driscoll, Rosalyn. "Aesthetic Touch”. Art and the Senses. Eds. Francesca Bacci and David Melcher. Oxford: Oxford UP, 2011. 107-14. Print.

Hurley, Erin. Theatre \& Feeling. Basingstoke and New York: Palgrave Macmillan, 2010.

Machon, Josephine. (Syn)aesthetics: Redefining Visceral Performance. Basingstoke and New York: Palgrave Macmillan, 2011. Print.

Machon, Josephine. Immersive Theatres: Intimacy and Immediacy in Contemporary Performance. Basingstoke and New York: Palgrave Macmillan, 2013. Print.

Marks, Laura. The Skin of the Film: Intercultural Cinema, Embodiment, and the Senses. Durham and London: Duke UP, 2000. Print.

Marks, Laura. Touch: Sensuous Theory and Multisensory Media. Minnesota: U of Minnesota P, 2002. Print.

Oddey, Alison and Christine White, eds. Modes of Spectating. Bristol and Chicago: Intellect, 2009. Print.

Pallasmaa, Juhani. The Eyes of the Skin: Architecture and the Senses. Chichester: John Wiley \& Sons, 2005. Print.

Pallasmaa, Juhani. The Thinking Hand: Existential and Embodied Wisdom in Architecture. Chichester: John Wiley \& Sons, 2009. Print. 
Schneider, Rebecca. The Explicit Body in Performance. London and New York: Routledge, 1997. Print.

Shaughnessy, Nicola. Affective Performance and Cognitive Science. Basingstoke and New York: Palgrave Macmillan, 2013.

Welton, Martin. Feeling Theatre. Basingstoke and New York: Palgrave Macmillan, 2011. Print.

\section{Practitioner References}

Adrian Howells: $\langle$ http://www.youtube.com/watch?v=C7btf8Tdg_s $>$ and $\langle$ http://www.youtube. com/watch?v=SLwD3APw2F8\&feature=relmfu>

Berlin Nevada: 〈http://silviamercuriali.com/projects/berlin-nevada/>

Coney: <http://coneyhq.org/>

dreamthinkspeak: <http://www.dreamthinkspeak.com>

II Pixel Rosso: <http://www.ilpixelrosso.org.uk/>

Lundahl \& Seitl: <http://www.lundahl-seitl.com/>

Punchdrunk: <http://punchdrunk.com/>

Rotozaza, Autoteatro: 〈http://www.rotozaza.co.uk/autoteatro.html>

Seth Kreibel's The Unbuilt Room: 〈http://www.unbuiltroom.com>

You Me Bum Bum Train (Kate Bond and Morgan Lloyd): 〈http://www.bumbumtrain.com>

\section{Bionote}

\section{Josephine Machon}

Middlesex University, j.machon@mdx.ac.uk

Josephine Machon is Senior Research Fellow in Contemporary Performance at Middlesex University, London. She has published widely on experiential and immersive performance and is the author of Immersive Theatres: Intimacy and Immediacy in Contemporary Performance (2013) and (Syn)aesthetics: Redefining Visceral Performance $(2009,2011)$. She is Joint Editor for the Palgrave Macmillan Series in Performance \& Technology, which includes her co-edited collections Performance and Technology (2006), Sensualities/Textualities and Technologies (2009) and Identity, Performance and Technology (2012). Her current research is concerned with impact and the audience in immersive theatres while her broad interests address the creative intersections of theory and practice in experiential performance. 